\section{Indústria \\ fonográfica \\ no RS: um futuro \\ possível}

Subsídios para a discussão sobre a implantação de um pólo industrial fonográfico no estado do Rio Grande do Sul.

Militão de Maya Ricardo

Mestre em Comunicação Social pela FAMECOS/PUCRS

Professor da FAMECOS/PUCRS

\section{Introdução}

ESTE TEXTO PRETENDE reunir alguns dados disponíveis sobre o mercado fonográ-fico brasileiro e gaúcho, para traçar rapidamente um quadro da sua atual situação. Em seguida apresenta sugestões sobre algumas diretrizes que podem nortear uma ação governamental e privada para traçar uma política de incentivo ao desenvolvimento estrutural do setor.

\section{Sifuação afual do mercado fono- gráfice no Brasil}

Não se pode ainda avaliar as conseqüências da crise econômica de 1998 sobre o consumo de CDs e espetáculos. O mercado brasileiro atravessava em 1997 uma fase de crescimento em relação aos anos anteriores.

Na segunda metade do século XX um dos ramos que mais prosperaram na indústria cultural brasileira foi o fonográfico, que a partir de 1970 abandonou seus índices de crescimento vegetativo e teve uma expansão vertiginosa. Entre 1970 e 1976 o faturamento das empresas fonográficas cresceu 1.375\%. ${ }^{1} \mathrm{Em} 1979$ foram vendidos mais de 39 milhões de discos, 8 milhões de fitas cassete e mais de 18 milhões de compactos simples e duplos. Vejamos o crescimento da venda de Lps e Cassetes na década de 70 (em milhares de unidades): ${ }^{2}$

$\begin{array}{cccc} & \text { Ano } & \text { Lps } & \\ \text { sete } & & & \\ 72 & 11.700 & 1.000 \\ 73 & 15.000 & 1.900 \\ 74 & 16.000 & 2.800\end{array}$




$\begin{array}{lll}75 & 16.900 & 3.900 \\ 76 & 24.000 & 6.800 \\ 79 & 39.252 & 8.481\end{array}$

A venda de discos de vinil aumentou $335,5 \%$ no período acima, enquanto a venda de cassetes cresceu $848 \%$. Isto é devido ao fato de que o cassete é uma tecnologia mais recente e a fita é mais fácil de manusear e transportar, fazendo um par perfeito com os toca-fitas portáteis e de automóveis.

Isto também foi resultado do crescimento econômico que o país teve naquela década, com uma grande expansão da indústria de eletrodomésticos, que acompanhou o ciclo econômico que era chamado pela ditadura militar de milagre brasileiro.

Embora não tenha havido uma redis-tribuição de renda significativa, uma parcela maior da população (que por sua vez cresceu) teve acesso aos aparelhos fono-gráficos eletrônicos e passou a comprar discos e fitas. Os anos 80 foram uma década de estagnação econômica no Brasil, com recrudescimento da inflação, que concentrou a riqueza nacional nas mãos de uma minoria da população e esfriou a capacidade do público de adquirir bens. Apenas no plano cruzado, em 1986, houve uma retomada do crescimento das vendas de discos, mas a euforia não durou muito tempo. No ano seguinte a inflação estava de volta e as vendas caíram novamente. Ao raiar da década seguinte o contraditório governo Collor tomou algumas medidas que impac-taram mais um pouco a indústria fonográ-fica em duas frentes: uma delas foi a queda das barreiras aduaneiras impostas aos equipamentos fonográficos domésticos e profissionais (incluídos aí os instrumentos musicais). A medida forçou a indústria nacional de eletrônicos domésticos (na verdade filiais das mesmas multinacionais que os produzem no exterior) a aumentar sua produtividade e baixar suas margens de lucro para oferecer mais qualidade e menor preço ao mercado, o que começou a acontecer por volta de 1992. Também permitiu que uma maior quantidade de músicos brasileiros tivesse acesso a instrumentos e equipamentos de gravação de melhor qualidade. Os estúdios de gravação aumentaram em número e em relação à qualidade dos equipamentos.

Os números de meados da década de 90, após o plano real apontam que o Brasil tem uma indústria de bens culturais de consumo fortemente consolidada, de grande porte e altamente competitiva em termos empresariais, na faixa das empresas de grande porte - as grandes gravadoras, a TV Globo, o SBT, a NET Brasil e a TVA, por exemplo. Com a queda dos preços dos eletroeletrônicos - entre eles o CD player $^{3}$ - e o pequeno aumento do poder de consumo das classes sociais mais pobres, a partir do controle da inflação conseguido com o plano real (a partir de 1994), o consumo de toca-discos (CD players) e de discos cresceu bastante no país. Em 1993 o mercado de $C D$ players foi de 600 mil unidades. No ano seguinte o número dobrou para um milhão e duzentos mil aparelhos. Em 1995 o salto foi de 125 por cento, resultando num total aproximado de 2.820 .000 players. Em 1996 as vendas atingiram a marca de 3 milhões e oitocentos mil unidades. ${ }^{4}$ Isto evidencia um grande e rápido aumento nos consumidores de compact discs.

Em 1992 foram vendidos 34 milhões de unidades de suportes de fonogra-mas (CDs, Cassetes e LPs), um resultado de vendas inferior ao registrado em 1979. Em 1995 foram comercializadas 75 milhões de unidades, num movimento de mais de $700 \mathrm{mi}-$ lhões de dólares, representando um aumento de mais de $100 \%$ em relação a 1992 . Com isto o Brasil passou a ser o sétimo mercado fonográfico do mundo, sendo que em 95 as vendas de discos de artistas estrangeiros representaram apenas $27 \%$ do total. ${ }^{5} \mathrm{Em}$ 1995 o mercado mundial de CDs faturou 39,7 bilhões de dólares, com dois bilhões de unidades vendidas. ${ }^{6} \mathrm{O}$ mercado brasileiro representou 1,76 por cento do faturamento e $3,75 \%$ das unidades vendidas naquele período.

Em 1996 o mercado fonográfico brasileiro cresceu $32 \%$ em relação ao ano anterior 
(em 95 já havia crescido outros $35 \%$ ). Foram vendidos aproximadamente 94 milhões de discos no país, ${ }^{7}$ com um fatura-mento de US\$ 874,25 milhões. ${ }^{8}$ O Brasil passou então para o sexto lugar no ranking mundial das vendas de discos, sendo que $72 \%$ das vendas foram de discos de produção nacional. ${ }^{9}$ As fitas cassete estavam sendo retiradas do mercado devido à pirataria ${ }^{10} \mathrm{e} \mathrm{o} L P$ de vinil estava quase extinto. ${ }^{11}$

$\mathrm{CD}$, agora ao alcance de uma faixa maior da população, representa $97 \%$ das vendas no Brasil. ${ }^{12}$ Sete grandes gravadoras multinacionais atuavam no país em 1997: Sony Music, Polygram, EMI, WEA (Warner), BMG, Universal e Virgin. As últimas duas instalaram-se aqui recentemente, atraídas pelo potencial de crescimento do mercado, o que vem se confirmando. O nível de vendagens e de negócios nesta faixa do mercado (a dos pesos-pesados) é alto.

Exemplos de artistas que atingem grandes vendagens de discos neste período são os grupos Mamonas Assassinas (que em 1995, antes de perecerem num trágico acidente de avião, venderam dois milhões de cópias de seu único CD), Skank, Parala-mas do Sucesso (o disco que sucedeu a Severino), que no mesmo ano venderam 750 mil CDs, ${ }^{13}$ e os Titãs, que até setembro de 1997 venderam também 750 mil cópias de seu CD Acústico, lançado neste mesmo ano. $^{14}$

Nos casos dos Titãs e do Skank, se for tomado como base de cálculo o preço médio de venda ao consumidor de $\mathrm{R} \$ 17,00$ por $\mathrm{CD}$, teremos um faturamento bruto estimado em R $\$ 12.750 .000,00$. No caso dos Mamonas Assassinas, a estimativa chega a $\mathrm{R} \$ 34.000 .000,00$. Isto dá uma idéia do potencial econômico da atividade fonográfica e artística.

Na verdade, além do talento é necessário um investimento grande para que um $C D$ venda tanto. Por trás do sucesso do CD Acústico dos Titãs está primeiramente a qualidade do trabalho. $\mathrm{O}$ talento do grupo é o princípio de tudo. Mas também houve um investimento de $\mathrm{R} \$ 1.750 .000,00$ (um milhão setecentos e cinqüenta mil reais) na produção de um novo trabalho e em divulgação através da mídia, divididos entre a gravadora Warner ( $R$ \$ 500 mil na produção do disco), a MTV (R\$ 500 mil na produção do show que originou o disco, que foi gravado para um programa especial da emissora) e o empresário Manoel Poladian (R 750 mil na produção do show e da turnê do grupo). Poladian comprou um pacote de shows (a $\mathrm{R} \$ 10$ mil cada) da banda, que estava afastada das paradas de sucesso há quatro anos, conseqüentemente com a agenda mais vazia e o custo do cachê reduzido. Após investimentos, show, disco, programa de TV e videoclipes veiculados, as músicas nas rádios, o público voltou aos shows e às lojas. Poladian agora cobra R $\$ 70$ mil por show. É um típico lance de um investidor: comprar um produto em baixa no mercado, retrabalhá-lo e vender quando estiver em alta. ${ }^{15}$ Os Titãs fizeram este trabalho acústico depois de uma série de trabalhos com a sonoridade pesada, que agradava a um público mais restrito. Foi uma concessão ao gosto médio do mercado. Mas o talento do grupo garantiu a qualidade do trabalho. Com a superexposição na mídia de massa o investimento deu retorno.

\section{1 - A dificuldade das pequenas em- presas do setor.}

O custo da duplicação industrial do CD de áudio também diminuiu nos últimos anos. Com cerca de dois ou três mil reais é possível hoje prensar 1.000 CDs numa fábrica brasileira. ${ }^{16}$. Mas não é tudo. Não basta fazer um disco. O dono da pequena gravadora paulista Tinitus e produtor musical, Pena Schmitt dá um depoimento importante:

“O acesso à gravação está mais fácil. Mas a gravação não significa que a música, a criação tenha se transformado num produto. (...) O estúdio é uma ponta muito pequena desta cadeia que 
é a indústria do entretenimento. Existem outros fatores como distribuição e divulgação. (...) A gravadora tem que estar imersa num universo maior de estoque, direitos autorais e pagamentos de músicas, distribuição." 17

Ainda se está distante da correta estruturação de mercados regionais ou segmentados no Brasil. Falta em primeiro lugar a visão de que uma gravação ainda não é um produto da indústria fonográfica. $\mathrm{O} C \mathrm{CD}$ será após passar por todas as etapas de tratamento industrial que o fonograma passa até chegar ao CD player da casa do ouvinte: planejamento, produção artística, gravação, prensagem, confecção da capa, divulgação, promoção, vendas, distribuição, pagamento de impostos, direitos autorais e assim por diante. Tudo isto contabi-lizado e administrado de forma organizada.

Mesmo numa pequena gravadora se está fabricando em série produtos da indústria fonográfica-cultural. Isto é tarefa para uma equipe de pessoas, para uma empresa. Uma pequena gravadora é mais uma empresa brasileira. E ela aí fica exposta a uma série de problemas que dificultam a vida das micro e pequenas empresas neste país. Falta uma política industrial e tributária que incentive as empresas deste porte. Faltam juros baixos, que permitam que se tome dinheiro emprestado para investir na produção. Mas, por outro lado também falta profissionalização, preparo administrativo, comercial e mercadológico.

A falta de estrutura administrativa e comercial e de logística de distribuição não é uma realidade apenas do mercado cultural brasileiro. As dificuldades da pequena empresa brasileira em geral são os mesmos e há vários anos existem alguns esforços para superá-los, como os que vem sendo feitos pelo sistema SEBRAE, que ministra cursos, dá treinamento e luta por políticas públicas que favoreçam a implantação e a existência da microempresa no Brasil. A maior dificuldade, porém é a péssima qualidade da educação básica e secundária no
Brasil, que forma trabalhadores pouco capacitados, dos quais muitos se tornam empresários criativos, dotados de espírito empreendedor porém incapazes de administrar eficazmente seus negócios nos quesitos básicos do funcionamento de uma empresa. O sintoma disto é que a cada ano abrem e fecham milhares de empresas no Brasil. A pequena indústria do ramo da cultura também precisa, assim como as empresas de outras áreas, se profissionalizar.

Falta também uma boa formação de mão-de-obra especializada para o mercado cultural. O Brasil carece de um ensino de arte que integre o artista ao ambiente da comunicação de massa, sua formas próprias de expressão estética e que os prepare com as ferramentas e técnicas próprias para atuar neste ambiente. Os cursos universitários de música que existem no Brasil em sua maioria ainda funcionam nos moldes dos conservatórios e academias européias de cem anos atrás. Dedicam-se em sua maioria à reprodução de um modelo de música erudita européia. Novas metodologias de ensino de musica e da tecnologia de gravação musical, como existem nos Estados Unidos, não chegaram até aqui, com excessão de poucas iniciativas particulares de pequeno porte. Estes métodos utilizam a música popular, que é estudada e utilizada no ensino. A tecnologia é um caso ainda mais grave. Não existem escolas de música que ensinem a utilização dos equipamentos musicais e de gravação musical. Tudo é aprendido através de esforço individual dos músicos ou em cursos no exterior. Não existe um curso superior para a formação de produtores musicais ou de engenheiros de gravação no Brasil, que no entanto possui uma indústria fonográfica de grande porte muito expressiva e uma cultura músical que atualmente é uma das mais ricas do planeta, ganhando prestígio de forma crescente em vários mercados no exterior. É comum o caso de artistas brasileiros que tem mais público na Europa do que no Brasil porque só conseguem gravar e divulgar seus trabalhos através de pequenas ou médias gravadoras eu- 
ropéias. Parece que estamos passando fome em meio a um pomar carregado porque não sabemos como colher as frutas.

2.2 - O Rádio, a TV e as grandes gravadoras: o gargalo.

O rádio é hoje no Brasil uma mídia menosprezada pela publicidade e alguns setores preponderantes da indústria cultural, onde impera a imagem. A exceção são as gravadoras e veremos porquê.

A facilidade de acesso aos aparelhos receptores de rádio, as características de sua linguagem e seu processo de recepção criam condições em que fazem com que seu alcance e sua contundência comunicativa sejam ainda muito grandes. A população brasileira em 1990 era de 150.367 .800 habitantes, dos quais $28 \%$ homens e mulheres entre 15 e 29 anos. Os segmentos sócio- econômicos A, B e C (entre 2 e mais de 20 pisos salariais) constituíam $38 \%$ da população. Em 1989, 98\% do público jovem (entre 15 e 29 anos tinha o hábito de ouvir rádio. Em 1988, o Brasil tinha 60.8 milhões de aparelhos receptores de rádio. ${ }^{18}$ Se este número tivesse se mantido estável até 1990, a população brasileira teria um aparelho de rádio para cada 2,5 habitantes. A força desta mídia é muito grande, ainda mais em um país com graves problemas de analfabetismo e semi-analfabetismo. O rádio também possui características que outras mídias visuais não tem: o de poder acompanhar o receptor no trabalho, no trânsito e por outros lugares, em função de sua portabilidade. Mesmo que a mídia impressa fale sobre os artistas, ela não tem a contundência da audição direta da obra musical e nem a abrangência de público que o rádio tem no Brasil.

O sistema de rádio é um dos pontos ${ }^{19}$ onde a diversidade musical é bloqueada e a viabilização dos mercados regionais da indústria cultural através de pequenas e médias empresas emperra. Devido ao fato de tocar música praticamente o dia inteiro (no caso das emissoras de FM em geral) o rádio é elemento chave para a diversificação do consumo fonográfico, embora a TV seja importante também. Na verdade, rádio e TV atuam em dupla: "após ouvir a música no rádio, a pessoa precisa visualizar o grupo ou o artista, por exemplo numa revista ou na TV para querer ir ao show e/ou comprar o disco", ${ }^{20}$ informa o gaúcho Vinicius Canto, empresário de artistas e produtor musical. Não é à toa que uma grande gravadora como a Polygram chegue a investir $\mathrm{R} \$$ $800.000,00$ na promoção de lançamento de um novo CD, como o do grupo É o Tchan. Esta verba será utilizada no que foi chamado de new jabá (o grifo é meu), ou seja, em promoções conjuntas com dezenas de emissoras de rádio do país. Com parte da verba a gravadora irá fornecer às emissoras de rádio brindes ${ }^{21}$ para que elas promovam sorteios entre seus ouvintes, e assim se mantenham bem colocadas na disputa pela liderança da audiência (o que lhes garante a locação dos espaços comerciais da programação, a fonte de suas receitas).

Há um vínculo muito forte entre boa parte das emissoras de rádio e as grandes gravadoras no Brasil. Existem nas majors equipes permanentes de divulgadores nas principais praças do mercado. Eles visitam as emissoras e os principais órgãos de imprensa semanalmente e entregam gratuitamente os novos lançamentos a programadores e críticos de música, para que sejam executados na programação e comentados pelos jornalistas especializados. As gravadoras de pequeno porte também tentam executar o mesmo sistema, mas seus discos raramente são executados pela maioria das rádios. Por quê?

Existe uma simbiose viciada entre as grandes gravadoras brasileiras e boa parte das emissoras de rádio que transmitem música. Isto influi diretamente sobre o teor da programação musical das emissoras de rádio e TV. Já houve em décadas passadas acusações nunca comprovadas, nem tampouco desmentidas, de suborno, ou seja, o pagamento de dinheiro aos programadores das rádios para que tocassem certas músi- 
cas, o que foi apelidado de jabá. Na presente pesquisa (de 1997) não foi comprovado o uso deste expediente. Hoje o new jabá (o grifo é meu) é mais sutil. As gravadoras fornecem gratuitamente os discos e brindes, materiais para promoções com o público e prestam alguns favores (o grifo é meu) para pessoas com poder de decisão sobre a programação das rádios. Em troca, as rádios tocam majoritariamente o material das grandes gravadoras, deixando praticamente nenhum espaço para discos de pequenas gravadoras ou de produção independente, com exceção de raros casos quando uma música destas vira sucesso espontaneamente. E ainda por cima veiculam as gravações de acordo com a estratégia traçada pelas próprias produtoras dos fonogramas, que exercem uma rigorosa vigilância sobre a veiculação através do Rádio Link. Katia Suman, gerente da rádio Ipanema FM de Porto Alegre, explica como isto funciona:

"O sistema funciona em todo o Brasil. As rádios que interessam a eles [as gravadoras] - e estas são as que têm audiência - são ouvidas todo o tempo pelo rádio link. Então o divulgador da gravadora chega aqui e diz:

- Olha, a nossa música de trabalho - que é trocada mensalmente - hoje é, por exemplo, 'Capitão de Indústria', com os Paralamas do Sucesso.

Então a criatura que fica lá ouvindo [no rádio link] vai anotar quantas vezes tocou 'Capitão de Indústria' em todas as rádios.

Através deste mecanismo eles controlam diariamente o número de execuções em cada emissora. Então ele chega e diz [para a emissora]: - Pô, tu não estás tocando a minha música." 22

O sistema da música de trabalho faz com que a mesma faixa de um disco seja ouvida na maioria das emissoras de rádio do país durante o mesmo período de tempo, favorecendo a memorização por parte do público ouvinte. Esta é uma faceta do nascimento de um sucesso do rádio. Daí se pode imaginar o que acontece no processo de elaboração da programação das emissoras que alardeiam tocar só sucessos.

\section{3. - Mercado Gaúcho}

O Rio Grande do Sul foi o terceiro mercado fonográfico do Brasil em 1996, quando foram vendidos 9,8 milhões de cópias de discos, correspondendo a $11 \%$ do total nacional. ${ }^{23}$

A situação da indústria fonográfica no Rio Grande do Sul é a mesma descrita no caso do Brasil, com algumas particularidades. Atualmente a principal e mais estru-turada atividade musical-fonográfica gaúcha acontece em torno do movimento nativista. Duas gravadoras lideram este mercado ACIT e USA Discos, seguidas pela RBS Discos e a RGE (que não é do estado). O Ciclo disco-rádio-TV-show funciona perfeitamente na música gauchesca. Emissoras de rádio de todo o estado veiculam as gravações e programa de TV em vários canais apresentam semanalmente programas musicais do gênero, formando e mantendo a atenção de um público que compra os discos e comparece aos shows. Vários grupos musicais exercem suas atividade regularmente, de forma profissional, com público no estado, na região sul, no centro-oeste e em outros estados do Brasil onde existem agrupamentos de migrantes gaúchos.

O rock, o samba aqui produzido e a MPG - música popular gaúcha (urbana) não conseguem completar o ciclo. Não conseguem espaço suficiente no rádio e na TV, apesar de que estes no Rio Grande do Sul terem um níveis de qualidade de programação e de estruturação empresarial bastante bons. ${ }^{24}$

Neste ambiente os produtores musicais e demais personagens desta tribo social convivem, criam e divulgam seus trabalhos pelos canais que encontram, porém não em escala e frequiência industrial.

A MPG gaúcha é esteticamente rica, porém ainda majoritariamente artesanal em 
relação ao processo de produção industrial, divulgação, vendas e distribuição.

Consequentemente não constitui atividade econômica rentável e não alcança expressão na economia do estado. É um desperdício de talento, de riqueza e de empregos.

Nos anos 90, com a chegada ao Brasil de equipamentos de gravação doméstica mais baratos e potentes se supunha que o caminho para a industrialização da música urbana gaúcha fosse possível mesmo em bases independentes ou através de pequenas empresas.

Mas o quadro é similar ao que encontramos no cenário nacional: o mercado não se estrutura de forma estável e rentável, por falta de espaço suficiente na mídia (apesar de existirem espaços privilegiados como a Ipanema FM e a FM Cultura em Porto Alegre), embora algumas coisas novas estejam acontecendo, como por exemplo a incursão da gravadora ACIT no campo da música urbana.

Em maio de 1997 a loja Toca do Disco tinha a venda 31 fitas de grupos (e estilos) diferentes. O campeão de vendas dos últimos tempos foi o CD Replicantes ao Vivo, de produção independente, que vendeu 1.000 cópias em três ou quatro meses, sendo que uns 100 na toca do disco ${ }^{25}$.

A banda Os Replicantes porém tem mais de dez anos de estrada e já teve maior exposição na mídia através de uma grande gravadora.

O número de emissoras de rádio e TV no RS é de cerca de 300 em outubro de 98, segundo a Associação Gaúcha de Empresas de rádio e TV-AGERT. O quadro geral de emissoras de radiodifusão do RGS é o seguinte:

TOTAL

$$
\text { Capital }
$$

Interior

$\begin{array}{ll}\text { RÁDIO AM } & 15 \\ \text { RÁDIO FM } & 16 \\ \text { TV } & 6\end{array}$

TOTAL

344
Fonte: Agert (www.agert.org.br), em 20/10/98.

Se veiculassem freqüentemente uma grande quantidade de música de todos os gêneros produzida no Rio Grande do Sul, estas emissoras, que cobrem todo o estado e assim constituem uma enorme e atuante vitrine, abririam um enorme mercado para a venda de discos e shows dos bons artistas atuantes no mercado regional gaúcho.

O estado tem um potencial enorme de artistas e publico que podem ser integrados num mercado fonográfico benéfico para todos, gerador de empregos, renda e dinamizador da economia. Para que se crie um pólo fonográfico forte no estado é preciso estruturar uma política integrada que contemple os aspectos enumerados a seguir, dentro de uma filosofia de ensinar a pescar em vez de dar o peixe.

\section{Direłrizes para uma ação gover- namental}

- Condições econômicas favoráveis para o nascimento e crescimento de micro e pequenas empresas.

- Trabalho de formação de uma mentalidade favorável à industrialização do disco e da música entre artistas e empresários. Superação de preconceitos que atrasam o desenvolvimento do setor.

- Profissionalização do setor - capaci-tação gerencial de artistas e capacitação cultural de empresários.

- Formação adequada de recursos humanos: produtores fonográficos, artísticos e administrativos. Engenheiros e técnicos de gravação.

- Abertura de espaço grande e permanente na mídia de massa eletrônica (rádio e TV) para os músicos que atuam com base no estado.

- Trabalho de formação do públicoouvinte na escola como alternativa à mídia comercial como formadora de repertórios. 
- Integração com o pólo cinematográfico do RS

- Incentivos à exportação de discos e espetáculos musicais. Participação em feiras da indústria fonográfica no Brasil e no exterior. Produção de um evento regional (a Feira de Música do Mercosul, ocorrida em 1998 em Canela, RS deveria ser mantida e ampliada).

- Conexão com a indústria do turismo

Ações em torno destes ponto estão mais detalhadas a seguir em forma de sugestões.

4.1 - Sugestões para a criação de um pólo fonográfico no RS:

1) Incentivar a criação de um mercado cultural saudável (regulado pelo estado), onde a competição desenfreada, não resulte em violenta acumulação de capital à custa da miséria de uma maioria numérica mas sim em oportunidades abrangentes para a produção e geração e a distribuição de riqueza.

2) Criar condições para quer os artistas locais tenham acesso à mídia de massa regional (principalmente rádio e TV) em condições de igualdade com os artistas nacionais ou contratados de grandes gravadoras. Sem farta veiculação na mídia de massa é impossível criar um mercado de massa, ou seja, economicamente viável para artistas e pequenas gravadoras. Algumas sugestões:

- Uma lei obrigando a veiculação de artistas locais nas emissoras de rádio (principalmente ) e TV situadas no estado talvez seja uma solução, embora de aplicação difícil. Deverá provocar uma reação dos proprietários de emissoras, figuras geralmente de grande poder político. Mesmo artistas podem se posicionar contra. Isto é uma ação polêmica.

- Um lobby do governo e dos artistas junto aos empresários do setor pode ser outra solução.

- Um forte movimento do governo e dos artistas contra o jabá (direto e indireto) também poderá ajudar.

- Incentivos às empresas que tocarem um determinado percentual $(30 \%$, por exemplo) de música de artistas de atuação local (esta é uma definição difícil...), ou de discos produzidos no estado/na região. Novamente uma definição muito subjetiva, que pode inviabilizar a aplicação de uma lei deste tipo.

- A criação de uma empresa/cooperativa de divulgação e distribuição, que reúna a produção de várias pequenas gravadoras, somando seus recursos para criar uma estrutura profissional semelhante as das grandes gravadoras para abrir espaço para os artistas na mídia e assegurar uma correta distribuição dos discos nas lojas de todo o estado, na região e até no país.

3) Uma política industrial e tributária que incentive as empresas do disco e do espetáculo, principalmente as de pequeno porte. (No Rio Grande do Sul a atual (1998) lei estadual de incentivo à cultura já atende isto).

4) Crédito disponível a juros baixos, que permita que se tome dinheiro emprestado para investir na produção.

5) Incentivar a profissionalização e o desenvolvimento gerencial, administrativo, comercial, logístico e mercadológico dos artistas e produtores fonográficos que já atuam no mercado através de curso, palestras, vídeos, seminários, etc em parceria com Universidades, SEBRAE, SENAC, etc.

6) Criar mecanismos (cursos através de parcerias com universidades) para a formação de novos engenheiros e técnicos de som, luz, gravação, produtores musicais, fonográficos, artísticos, administrativos (especializados no negócio da cultura) e empresários especializados em show busi-ness.

7) Incentivar uma formação dos economistas e administradores que lhes dê sensibilidade em relação à cultura, ou pelo menos uma abertura de visão para o potencial econômico e social da arte.

8) Incentivar através de campanhas institucionais, seminários, publicações, ví- 
deos, palestras, etc, uma nova mentalidade do artista que já atua, para que ele aceite o paradigma industrial da obra de arte e entenda que precisa ter conhecimentos mínimos de administração, comércio e marketing para assegurar a sua própria liberdade de criação. Um trabalho de longo prazo deve ser feito nas escolas de arte, inicialmente e depois nas escolas de administração, para mostrar aos artistas em formação e futuros administradores o potencial da indústria da arte e do entretenimento.

9) Procurar inserir no currículo dos atuais cursos universitários de música e/ou comunicação existentes no estado o ensino das técnicas e ferramentas de gravação, edição musical e gerenciamento de negócios do show business e do mercado fonográfico.

10) Criar uma outra instância (a única existente é a mídia de massa comercialprivada) de formação da cultura musical pessoal dos cidadãos gaúchos: a escola! Trabalhar em conjunto com a secretaria de educação, a TV e a Rádio Cultura e o Canal Futura para inserir nos currículos dos cursos de primeiro e segundo grau a formação de um repertório de conhecimentos sobre gêneros musicais variados. Fazer com que o jovem escute e conheça a música na escola, principalmente dos artistas locais, para que depois faça suas opções de audição a partir de um cardápio mais diversificado do que é servido pela mídia de massa. Este é um trabalho de longo prazo.

11) Promover uma integração do pólo fonográfico com o pólo cinematográfico do RS. A produção de um filme necessita da criação e produção de uma trilha sonora e musical. Além disto certas trilhas musicais ajudam a promover um filme. O pólo fonográfico e o pólo cinematográfico se reforçam e se ajudam mutuamente.

12) Incentivar a exportação de discos e espetáculos musicais gaúchos. Participação de empresas e artistas em feiras e eventos nacionais e internacionais da indústria fonográfica e do turismo. Divulgação do pólo fonográfico nas missões comerciais do estado. Auxílio à exportação através do Balcão

\section{SEBRAE.}

13) Conexão do pólo da indústria fonográfica-musical com a indústria do turismo no estado. Eventos musicais são um forte atrativo turístico. Os músicos que atuam regionalmente são uma marca única e original da cultura do estado, constituindo-se assim uma atração turística a mais. Esta, por sua vez é uma fonte de renda suplementar para os artistas •

\section{Notas}

1 "Disco em São Paulo", Pesquisa 6, IDART, 1980 . In: Ortiz, Renato. A Moderna Tradição Brasileira: Cultura Brasileira e Indústria Cultural. São Paulo, Brasiliense, 1988. p.127.

2 Associação Brasileira de Produtores de Discos. In: Ortiz, Renato., Op. Cit. p.127.

3 Fonógrafo que reproduz sons e música armazenados em um compact disc através do processo digital. A corrente mania brasileira pelos anglicismos de linguagem fez com que não se nacionalizasse 0 termo.

4 FERNANDES, Fátima. "Brinde de CD embala setor fonográfico". Folha de São Paulo. São Paulo, 20/10/1997. Recolhido via internet, no endereço http:// www.uol. com. $\mathrm{br} / \mathrm{fsp} /$ dinheiro/fl201006.htm.

5 "Explosão Nacional". Revista Veja, edição de 20/3/1996. São Paulo, Abril. pp. 114 a 116.

6 MONTEIRO, Marion. "Sábado de Compras". Jornal do Brasil. Rio de Janeiro, 20/07/96. Caderno Negócios e Finanças, p.13.

7 FERLA, Marcelo. "Barulhinho bom na caixa registradora". Jornal Zero Hora. Porto Alegre, 15/1/1997. pp. 4 e 5.

8 FERNANDES, Fátima. Op. Cit.

9 ESSINGER, Silvio. "CD, o objeto sonoro do desejo". Jornal do Brasil. Rio de Janeiro, 21/9/97. Caderno B, p. 6.

10 A pirataria - o mercado de fitas cassete copiadas ilegalmente, sem pagar direitos autorais e impostos - atingiu tamanha proporção no Brasil que as gravadoras pararam 
de lançar títulos neste formato.

110 desaparecimento do toca-discos, que reproduz o som a partir dos discos de vinil, está condicionado ao aumento do poder aquisitivo dos públicos de baixa renda. Quando isto acontece as pessoas compram aparelhos de CD para substituir os antigos toca-discos de vinil. O contrabando de aparelhos eletrônicos baratos trazidos do Paraguai e vendido nas ruas por camelôs também possibilitou que as populações pobres tivessem acesso aos CD Players e ajudou o crescimento do mercado de CDs no Brasil.

12 ESSINGER, Silvio. Op. Cit p.6.

13 "Explosão Nacional". Revista Veja, edição de 20/3/1996. São Paulo, Abril. pp. 114 a 116.

14 PIMENTA, Angela e SANCHES, Neusa. Talento para fazer milhões. Veja, São Paulo. Edição de 3/9//1997. pp. 128 a 132.

15 PIMENTA, Angela e SANCHES, Neusa. Op. Cit. pp. 128 a 132.

16 "Uma turma de idéias". Veja, 26/7/1995. p. 115. e DAL SANTO JR., Egisto, em depoimento ao autor.

17 SCHMIDT, Pena, em entrevista ao autor.

18 Anuário Brasileiro de Mídia, edição 1990/91. São Paulo, SP. Ed. Meio e Mensagem.

19 Os outros pontos nevrálgicos são as escolas que não dão uma formação musical abrangente às pessoas e as lojas, como foi comentado.

20 CANTO, Vinicius, em entrevista ao autor.

21 Shortinhos e botinhas no mesmo estilo das utilizadas pelas bailarinas do grupo e pacotes de viagens ao Egito (o figurino da nova produção do grupo de samba é inspirado num harém). Fonte: PIMENTA, Angela e SANCHES, Neuza. Talento para fazer milhões. Veja. São Paulo, 3/9/97. p130.

22 SUMAN, Katia, em entrevista ao autor.

23 ALBUQUERQUE, Eliete. "Estado atrai redes nacionais de Cds: Grandes lojas mexem com o mercado gaúcho". Consumo - Jornal da Federasul. Porto Alegre, 22/9/1997, p.1.
24 A RBS - Rede Brasil Sul é a maior rede regional de televisão do Brasil. Uma empresa que atua no mercado de comunicação (jornal, TV, rádio, TV a cabo e internet) e telecomunicações (CRT) e construção civil (Maiojama) com bastante profissionalismo e com sólida e ativa estrutura administrativa comercial. Sua rede de emissoras de TV cobre os estados do Rio Grande do Sul e Santa Catarina. A rede de emissoras de FM está presente nas maiores cidades dos dois estados. A RBS Tvretransmite a programação da TV Globo, mas apresenta há 15 anos o programa Galpão Nativo, de produção local, onde se apresentam músicos ligados ao gênero nativista-rural. Estranhamente a música urbana não teve a mesma atenção.

25 Os CDs de Solón Fishbone e Frank Solari também venderam em torno de 100 Cds na toca do disco. fonte: Cazzetta, Rogério, proprietário da Toca do Disco, em depoimento ao autor.

\section{Referências}

Anuário Brasileiro de Mídia, edição 1990/91. São Paulo, SP. Ed. Meio e Mensagem.

ETELVEIN, Gilmar. A música de Porto Alegre: 0 Rock - anos 50, 60, 70 e 80. Porto Alegre, Secretaria Municipal de Cultura, 1994.

ETELVEIN, Gilmar. Fughetti Luz. O Rock Gaúcho. Porto Alegre, Edição do autor, 1996.

MORIN, Edgar. Cultura de Massas no Século XX. O Espirito do Tempo. Rio de Janeiro, Forense. 1967.

ORTIZ, Renato. A Moderna Tradição Brasileira: Cultura Brasileira e Indústria Cultural. São Paulo, Brasiliense, 1988.

MONOGRAFIAS E DISSERTAÇÕES ACADÊMICAS

ANTONIUTTI, Daniela Mascarenhas. "A Rádio Atlântida FM de Porto Alegre e a sua veiculação comercial no período de julho de 89 a junho de 91". Porto Alegre, 1991. Monografia (Graduação), Faculdade dos Meios de Comunicação Social, PUC-RS.

FERREIRA, Clodomir Souza. "Uma Gota: Assim A Chuva Começa. Estudos de casos de produção de discos independentes em Brasília". Brasília, 1991. Dissertação (Mestrado). 
Universidade de Brasília, 1991. (Cópia xerográfica).

RICARDO, Militão de Maya. "Disco para ser voador tem que decolar... Um estudo sobre comunicação de massa e a indústria fonográfica". Porto Alegre, 1997. Dissertação (Mestrado). Pontifícia Universidade Católica do RS: Faculdade dos meios de Comunicação Social (FAMECOS), 1997. (Cópia xerográfica).

\section{ENTREVISTAS}

SCHMIDT, Pena. Entrevista ao autor.

CANTO, Vinicius. Entrevista ao autor.

CAZZETA, Rogério. Entrevista ao autor.

SUMAN, Katia. Entrevista ao autor.

\section{INTERNET}

ALBUQUERQUE, Eliete. "Estado atrai redes nacionais de Cds: Grandes lojas mexem com o mercado gaúcho". Consumo - Jornal da Federasul. Porto Alegre, 22/9/1997, p.1.

ESSINGER, Silvio. "CD, o objeto sonoro do desejo". Jornal do Brasil. Rio de Janeiro, 21/9/97. Caderno B, p. 6.

"Explosão Nacional". Revista Veja, edição de 20/3/1996. São Paulo, Abril. pp. 114 a 116.

FERLA, Marcelo. "Barulhinho bom na caixa registradora". Jornal Zero Hora. Porto Alegre, 15/1/1997. pp. 4 e 5.

FERNANDES, Fátima. "Brinde de CD embala setor fonográfico". Folha de São Paulo. São Paulo, 20/10/1997. Recolhido via internet, no endereço http://wwww.uol.com.br/fsp/dinheiro/ fl201006.htm.

MONTEIRO, Marion. "Sábado de Compras". Jornal do Brasil. Rio de Janeiro, 20/07/96. Caderno Negócios e Finanças, p.13.

PIMENTA, Angela e SANCHES, Neuza. "Talento para fazer milhões". Veja. São Paulo, 3/9/97. p130.

\section{DEPOIMENTOS}

RENY, Júlio. Nas ondas do Rádio. Depoimento prestado no debate promovido pela Secretaria de Estado da Cultura do Rio Grande do Sul. Porto Alegre, 30/5/1996. Anotações do autor.

WEIRAUCH, Carlos Eduardo. Nas ondas do Rádio. Depoimento prestado no debate promovido pela Secretaria de Estado da Cultura do Rio Grande do Sul. Porto Alegre, 30/5/1996. Anotações do autor.
WEB SITE DA AGERT - Associação Gaúcha de Emissoras de Rádio e TV. (www.agert.org.br) , em 20/10/98. 